\title{
Decreased motility of human spermatozoa presenting phosphatidylserine membrane translocation-cells selection with the swim-up technique
}

\author{
Malgorzata Kotwicka $\cdot$ Magdalena Jendraszak • \\ Izabela Skibinska • Piotr Jedrzejczak • \\ Leszek Pawelczyk
}

Received: 27 April 2011 / Accepted: 9 June 2011/Published online: 3 July 2011

(c) The Author(s) 2011. This article is published with open access at Springerlink.com

\begin{abstract}
Phosphatidylserine membrane translocation (PST) is considered to be a marker of apoptosis; however, numerous studies have reported on its role in processes not related to cell death. The purpose of the study was to investigate: (1) what is the impact of PST on the motility of spermatozoa, and (2) does the swim-up isolation involve the percentage of cells presenting PST? Semen of 28 normozoospermic men (WHO criteria) was analyzed. High motility spermatozoa were isolated by the swim-up technique. The percentage of spermatozoa with PST in neat semen and after swim-up isolation was assessed with Annexin-V labeled with fluorescein, using flow cytometry technique. The spermatozoas' motility was measured with a computer-assisted analysis system. The kinetic subpopulations of spermatozoa were identified with dedicated software and analyzed regarding PST. Vital spermatozoa with PST demonstrated progressive movement. The motion analysis system revealed a very strong positive correlation between the percentage of vital spermatozoa with PST and the percentage of spermatozoa belonging to the slow subpopulation ( $r=0.83 ; p<0.05)$, as well as a very strong negative correlation between the percentage of vital spermatozoa with PST and the percentage of spermatozoa belonging to the rapid subpopulation $(r=-0.86$; $p<0.05)$. After the swim-up isolation, the percentage of vital spermatozoa presenting PST significantly decreased $(2.4 \pm 2.1 \%$ vs. $5.2 \pm 2.4 \% ; p<0.05)$. Spermatozoa with PST present progressive movement; however, their motility is
\end{abstract}

M. Kotwicka $(\square) \cdot$ M. Jendraszak · I. Skibinska Department of Cell Biology, Poznan University of Medical Sciences, Rokietnicka 5D, 60-806 Poznan, Poland e-mail: mkotwic@ump.edu.pl

P. Jedrzejczak $\cdot$ L. Pawelczyk

Department of Infertility and Reproductive Endocrinology, University of Medical Sciences, Poznan, Poland decreased. Isolation of spermatozoa with the swim-up technique eliminates the cells with PST.

Keywords Phosphatidylserine membrane translocation . Spermatozoa $\cdot$ Motility

\section{Introduction}

Asymmetry of the arrangement of phospholipids throughout the lipid bilayer is a distinctive feature of biological membranes. Phospholipids containing choline such as phosphatidylcholine and sphingomyelin are present in the outer layer of the plasma membrane. Aminophospholipids such as phosphatidylethanolamine (PE) and phosphatydilserine (PS) are placed in the inner part [1-3]. Asymmetry of the arrangement of phospholipids within the membrane is not absolute except for phosphatidylserine which is controlled by fippase activity $[4,5]$. The process of phosphatidylserine membrane translocation (PST) consists of translocation from the inner to the outer membrane leaflet and is recognized to be an important biological event within the cell.

PST occurs in apoptotic cells [6]. It is suggested that decrease of fippase activity can be found in cells which were given the apoptotic signal. It is assumed that increased intracellular $\mathrm{Ca}^{2+}$ concentration inhibits fippase activity while inducing scramblase activity [7]. It is supposed that PS exposed on the cell surface is an element of the "eat me" signal, which is sent to macrophages; however, the exact nature of the signal causing migration of macrophages to the apoptotic cells localization remains unclear. It is supposed that binding of PS with the PS receptor localized on phagocytes does not directly result in phagocytosis but represents a tickling signal that stimulates tethering of an apoptotic cell $[8,9]$. 
Several studies have shown that PST can take place not only during apoptosis but also at various stages of cell differentiation [10-12]. Van den Eijnde et al. [13] reported that differentiating myoblasts demonstrated superficial PS expression. The authors postulated that superficial expression of fusiogenic lipids (PS and PE) might be necessary for the fusion process leading to formation of polynuclear muscular fibers. PS externalization also concerns membrane lipid rafts of developing and mature lymphocytes B [14]. PS externalization was identified at some stages of erythropoiesis as an important element of the blood-clotting process cascade [15-17]. Superficial PS expression was found in erythrocytes of patients diagnosed with thalassemia [18, 19], chronic renal failure [20] and sicklecell anemia [21]. It has also been described in aging erythrocytes; thus, it could be a signal for eliminating aging or abnormal cells [22-24].

The cell membrane of human spermatozoa, as well as the one of the somatic cells, show outer-inner asymmetry of the lipid bilayer. The topography of the spermatozoon cell membrane comprises five main domains which differ regarding the occurrence of PST $[25,26]$. Present data do not clearly explain the circumstances under which PST occurs in spermatozoa or what are the biological effects of this process. It is suggested that PST can be considered an exponent of changes in the spermatozoa cell membrane that occur during capacitation and acrosome reaction or during elimination of pathological spermatozoa.

The purpose of the study was to investigate the impact of PST on the motility of the spermatozoa. The following issues were addressed: (1) is there a relationship between PST and the spermatozoa's motility, and (2) does the swim-up isolation involve the percentage of cells presenting PST?

\section{Materials and methods}

\section{Selection criteria}

Human semen from 28 normozoospermic men was obtained. Semen analysis was performed according to the World Health Organization guidelines. Unprocessed (neat) semen samples were washed in phosphate-buffered saline (PBS). Spermatozoa with high motility were isolated by the swim-up technique (WHO 1999) [27].

Plasma membrane translocation of phosphatidylserine assay

The translocation of PS from the inner to the outer leaflet of the plasma membrane was detected using annexin $\mathrm{V}$ $(\mathrm{An}-\mathrm{V})$ marked with fluorescein (An-V-FLUOS) (cat.
1828681; Roche, Germany). To differentiate between the vital and the dead cells propidium iodide (PI) (cat. P4170; Sigma-Aldrich, USA) was used. Spermatozoa resuspended in PBS were prepared according to the manufacturer's instructions for cell suspension.

Microscopic observation were made under a confocal microscope (LSM 510; Zeiss, Germany). The fluorescence signals of labeled spermatozoa were analyzed by flow cytometer FACSCalibur (Becton-Dickinson, USA). For each experiment, 10,000 spermatozoa were examined. The fluorescence of An-V-FLUOS and PI was excitated by argon laser $(488 \mathrm{~nm})$ and emission of An-V-FLUOS was measured in the FL1 channel (515-545 nm), while the red fluorescence of PI was detected in the FL3 channel $(>650 \mathrm{~nm})$. All data were collected and analyzed using CellQuest Pro software (v.5.2.1) (Becton-Dickinson). For each experiment, density dot plots were drawn.

\section{Analysis of spermatozoa motility parameters}

Spermatozoa motility analysis was performed using a computer-assisted spermatozoa analysis system. Ten $\mu \mathrm{l}$ of spermatozoa suspension was spotted on a Cell Vision chamber slide, which gives the permanent thickness of the specimen. The picture registration was conducted with a frequency of 60 frames per second using a PixelLink camera. The motility of a minimum 10 different fields of the microscopic specimen was registered for each case, so that the number of analyzed spermatozoa could not be lower than 700 cells. Acquisition time was $2.08 \mathrm{~s}$. The analyzed area was of $640 \times 470 \mu \mathrm{m}$ in size, at 0.86 points of resolving power. Trajectory motility analysis was performed with the use of "C-Ruch" software [28]. All measurements were made in a constant, controlled temperature of $24^{\circ} \mathrm{C}$. The following spermatozoa motility parameters were analyzed: (1) velocity straight linear (VSL), (2) cross-beat frequency (CBF), (3) lateral head displacement (LHD) and (4) homogeneity of progressive movement velocity (HPMV).

To highlight motile subpopulations from the examined sperm population, the "C-Ruch" computer program was used. The selection rule used in this program is based on adjusting the VSL value distribution by means of multiple normal distribution. Each distribution is characterized by the mean VSL value of the subpopulation, standard VSL deviation and the percentage of spermatozoa belonging to each subpopulation. The number of the subpopulation was not given a priori and resulted from the quality of adjustment towards the real distribution. The number of subpopulations and their values regarding VSL were calculated. Other motility parameters were calculated using projection weighted by probability of belonging to the subpopulation. 
Statistical analysis

Evaluation was performed by nonparametric tests (Wilcoxon rank-sum test, Spearman correlation). Calculations were performed using Statistica 7.0 (StatSoft). $p<0.05$ was considered significant.

\section{Results}

Microscopic and flow cytometric analysis distinguished four fractions of spermatozoa: (1) $\mathrm{AnV}^{-} / \mathrm{PI}^{-}$(vital sperm cells without membrane PST), (2) $\mathrm{AnV}^{+} / \mathrm{PI}^{-}$(vital cells with membrane PST), (3) $\mathrm{AnV}^{-} / \mathrm{PI}^{+}$(dead cells without membrane PST) and (4) $\mathrm{AnV}^{+/} \mathrm{PI}^{+}$(dead cells with membrane PST).

The midpiece was the most frequent site of PST in vital spermatozoa. Spermatozoa with PST in the midpiece demonstrated the ability for progressive movement (Fig. 1). Spermatozoa with PST in both midpiece and the acrosomal region lost the ability for progressive movement. The ability of slow progressive movement was also noticed in single spermatozoa with PST located in the midpiece and in accumulation of PI in the nucleus.

In order to estimate the dependence between spermatozoa motility and PST, the percentages of spermatozoa demonstrating PST and presenting a chosen value of motility parameters, namely the VSL, CBF, LHD and HPMV, were evaluated. Because of significant heterogeneity of progressive movement velocity of spermatozoa (Table 1), various motility subpopulations were distinguished in each semen sample. According to the VSL value for each aliquot of neat semen, three kinetic fractions of sperm were observed: slow, moderate and rapid (Table 1). For each semen, the percentage of spermatozoa in each kinetic fraction was assessed.

A very strong positive correlation $(r=0.83 ; p<0.05)$ was found between the percentage of $\mathrm{AnV}^{+} / \mathrm{PI}^{-}$spermatozoa in neat semen and the percentage of slow sperm fraction, while a very strong negative correlation was found between the percentage of rapid spermatozoa fraction and the percentage of $\mathrm{AnV}^{+} / \mathrm{PI}^{-}$spermatozoa $(r=-0.86$; $p<0.05$ ) (Fig. 2). There was no significant correlation the between percentage of vital spermatozoa with PST and the
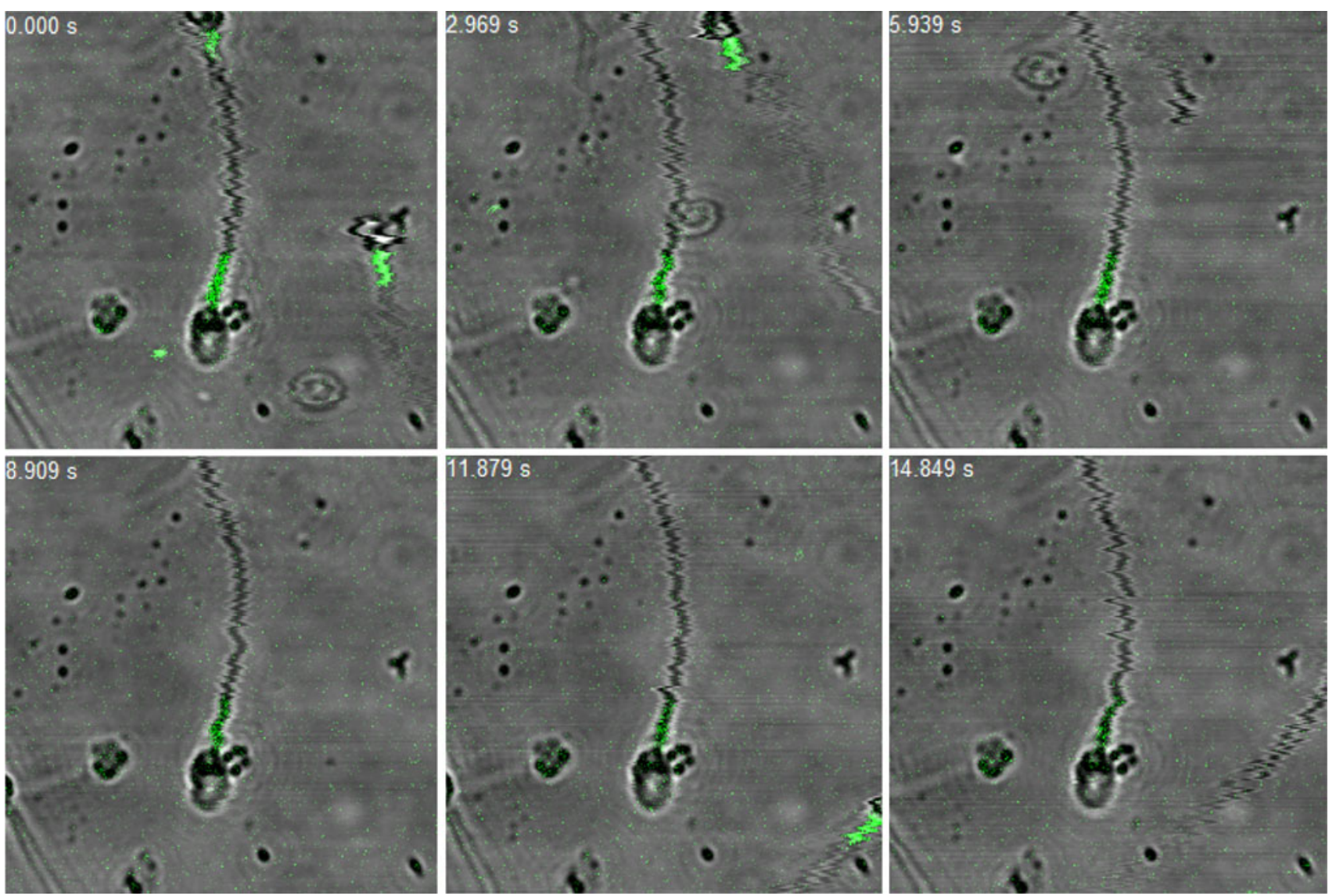

Fig. 1 A sequence of confocal microscopy images showing moving spermatozoa with phosphatidylserine translocation in the midpiece; annexin-V fluorescein isothiocyanate staining 
Table 1 Chosen values of spermatozoa motility parameters from exemplary neat semen

\begin{tabular}{|c|c|c|c|c|c|}
\hline & \multicolumn{5}{|c|}{ VSL, CBF, LHD, HPMV values for all spermatozoa } \\
\hline & $n$ & Mean & Minimum & Maximum & Standard deviation \\
\hline VSL $(\mu \mathrm{m} / \mathrm{s})$ & 772 & 19.95 & 2.94 & 37.98 & 9.00 \\
\hline $\mathrm{CBF}(\mathrm{Hz})$ & 772 & 3.56 & 0.52 & 26.93 & 3.64 \\
\hline LHD $(\mu \mathrm{m})$ & 772 & 1.66 & 0.24 & 3.76 & 0.88 \\
\hline \multirow[t]{3}{*}{ HPMV $(\mu \mathrm{m})$} & 772 & 2.11 & 0.31 & 11.88 & 1.40 \\
\hline & \multicolumn{5}{|c|}{ VSL, CBF, LHD, HPMV values of separated spermatozoa kinetic subpopulations } \\
\hline & $(\%)$ & VSL $(\mu \mathrm{m} / \mathrm{s})$ & $\mathrm{CBF}(\mathrm{Hz})$ & LHD $(\mu \mathrm{m})$ & HPMV $(\mu \mathrm{m})$ \\
\hline Slow fraction & 31.2 & $6.5 \pm 1.3$ & $4.2 \pm 4.7$ & $0.4 \pm 0.1$ & $0.9 \pm 1.3$ \\
\hline Medium fraction & 19.6 & $11.6 \pm 2.2$ & $4.5 \pm 2.8$ & $0.6 \pm 0.2$ & $1.3 \pm 2.1$ \\
\hline Rapid fraction & 49.2 & $22.7 \pm 9.8$ & $3.2 \pm 1.6$ & $1.7 \pm 0.8$ & $1.9 \pm 0.9$ \\
\hline
\end{tabular}

VSL Velocity straight linear, $C B F$ cross-beat frequency, $L H D$ lateral head displacement, $H P M V$ homogeneity of progressive movement velocity

a

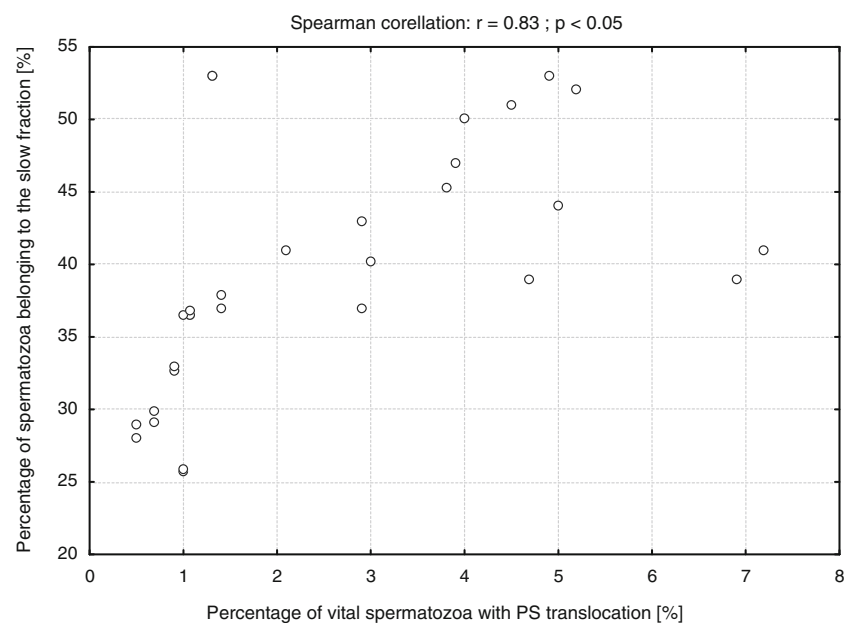

b

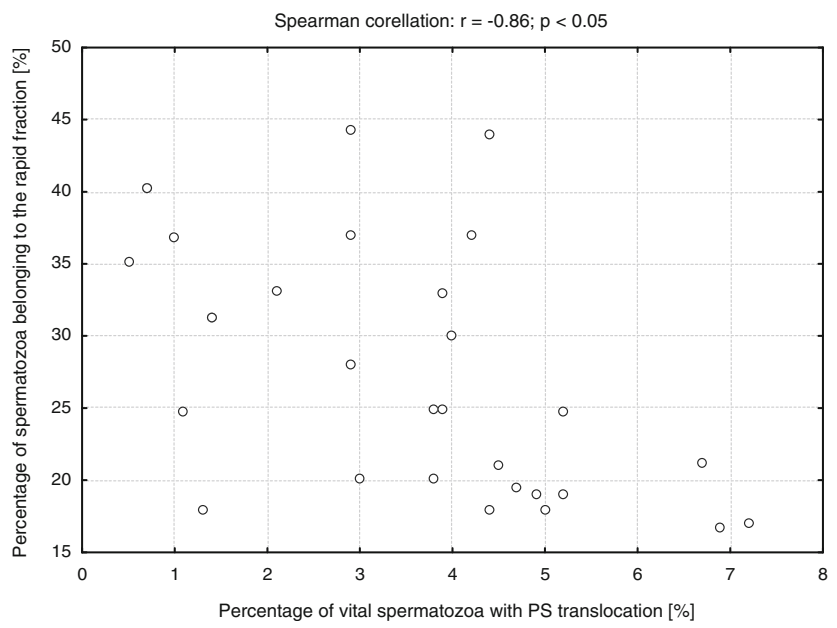

Fig. 2 Correlation between the percentage of vital spermatozoa with PST and the percentage of spermatozoa belonging to the slow fraction (a) and to the rapid fraction (b) in neat semen for 28 normozoospermic men

percentage of moderate VSL spermatozoa kinetic fraction $(p>0.05)$.

Flow cytometry analysis demonstrated that, in the swimup fraction, the amount of vital spermatozoa with PST was significantly reduced comparing to neat semen: $2.4 \pm 2.1$ versus $5.2 \pm 2.4 \%, p<0.05$ (Table 2). The distribution of spermatozoa fractions in neat semen and after swim-up selection in an exemplary normozoospermic semen is presented in Fig. 3.

\section{Discussion}

Our observations indicate that spermatozoa with PST within the midpiece reveal the ability for progressive
Table 2 Percentage of spermatozoa with phosphatidylserine membrane translocation in neat semen versus the percentage in the swimup isolation fraction for 28 normozoospermic men

\begin{tabular}{lccl}
\hline Type of spermatozoa & $\begin{array}{l}\text { Neat semen } \\
\text { Mean } \pm \text { SD }(\%)\end{array}$ & $\begin{array}{l}\text { Swim-up fraction } \\
\text { Mean } \pm \text { SD }(\%)\end{array}$ & $p$ \\
\hline $\mathrm{An}-\mathrm{V}^{-} / \mathrm{PI}^{-}$ & $64.4 \pm 12.0$ & $91.7 \pm 6.0$ & $<0.05$ \\
$\mathrm{An}-\mathrm{V}^{+} / \mathrm{PI}^{-}$ & $5.2 \pm 2.4$ & $2.4 \pm 2.1$ & $<0.05$ \\
$\mathrm{An}-\mathrm{V}^{+} / \mathrm{PI}^{+}$ & $21.8 \pm 12.5$ & $3.5 \pm 1.2$ & $<0.05$ \\
$\mathrm{An}-\mathrm{V}^{-} / \mathrm{PI}^{+}$ & $8.5 \pm 4.5$ & $2.7 \pm 0.8$ & $<0.05$ \\
\hline
\end{tabular}

SD Standard deviation

movement. On the other hand, a significant reduction of percentage of vital spermatozoa with PST in the fraction isolated with the use of swim-up was observed. These findings demonstrate that spermatozoa with PST preserve 


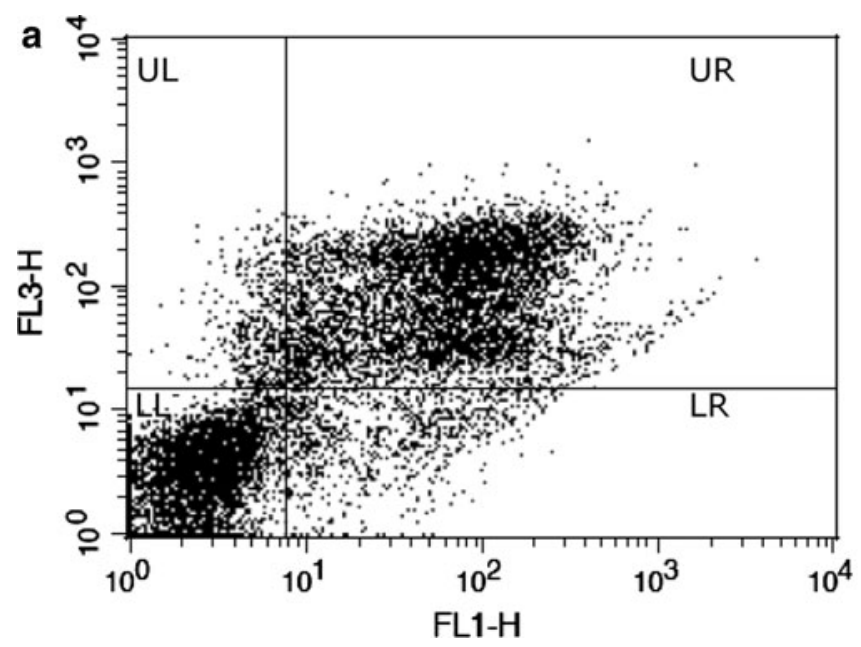

Fig. 3 Flow cytometric analysis of spermatozoa with PST (annexinV-FLUO staining) with their vitality taken into consideration as well (PI staining) in neat semen (a) and after swim-up selection (b) in exemplary semen of normozoospermic man. On the density plot, the cells are identified as follows: upper left quadrant $(U L)$ cells binding

the ability of progressive movement; however, their motility parameters decrease. Negative correlation between the percentage of the rapid spermatozoa subpopulation and the percentage of spermatozoa with PST supports that hypothesis.

Paasch et al. [29] noticed a significant decrease of percentage of spermatozoa with the ability for progressive movement and a decrease of the VSL and VCL values, when using the annexin-V-conjugated magnetic balls method. However, other reports do not confirm any relationship between PST and the motility of spermatozoa. Perticarari et al. [30] did not observe any correlation between the percentage of spermatozoa with PST and the percentage of spermatozoa able to move progressively. Those authors suspect that some spermatozoa with PST are able to move, while others are not. Perticarari et al. suggest that at early stages of the apoptosis process, considering PST as an apoptosis index, the motility of spermatozoa can remain unchanged.

This study demonstrated that spermatozoa with PST in the midpiece showed an ability for progressive movement, while those with PST in both the midpiece and the apical region lost that ability. Barroso et al. [31] reported that the decrease of motility parameters of spermatozoa with PST is connected with a decrease of mitochondrial potential. It seems that changes of motility parameters and PST can be connected with a decrease of the adenosine triphosphate (ATP) level in spermatozoa. Only spermatozoa with midpiece PST showed the ability for progressive movement. Therefore, it seems that mechanisms affecting membrane PST in the midpiece and the mechanisms of motility parameters decrease are not directly connected. It can be

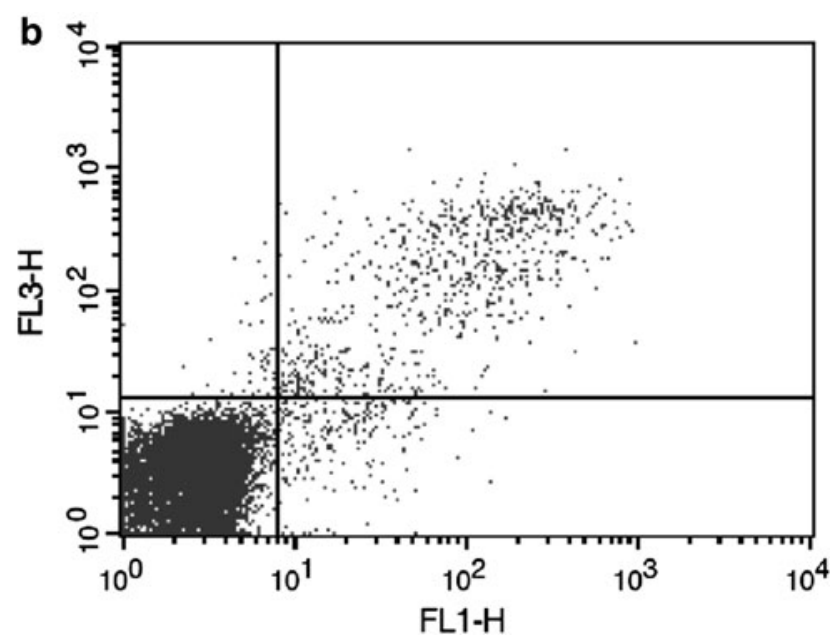

only PI, upper right quadrant (UR) cells binding both annexin-V and PI, lower left quadrant $(L L)$ unstained cells, lower right quadrant $(L R)$ cells binding only annexin-V. FL1-H fluorescence channel $515-545 \mathrm{~nm}, F L 3-H$ fluorescence channel $>650 \mathrm{~nm}$

assumed that the maintenance the ability of the tail to move, apart from the mitochondrial potential decrease, is connected to ATP gained in glycolysis. The flagellum is a long (ca. $50 \mu \mathrm{m}$ in humans) and thin (ca. $0.5 \mu \mathrm{m}$ in diameter) structure [32]. Mitochondria, which generate most of the cell ATP supply in the oxidative phosphorylation process, are accumulated in the proximal region of the tail. The question arises whether ATP diffusion from mitochondria to the distal parts of the tail is fast enough to accommodate motility needs. Data show that glycolytic enzymes present in spermatozoa are localized just in the main part of the tail and some of them are connected with fibrous areola [32]. Until now, four enzymes from that group (specific for spermatozoa) have been identified: hexokinase1 (HK1), Glyceraldehyde 3-phosphate dehydrogenase (GAPDHS), aldolase A isoform (ALDOA) and lactate dehydrogenase (LDHA) [33, 34]. The essential role of glycolytic transformations in spermatozoa motility has been shown in observations on mice with GAPDHS nocaut. In that case, the mice spermatozoa lost the ability for progressive movement [32]. Moreover, the presence of a unique carrier protein, sperm flagellar energy carrier (SFEC, AAC4), has been discovered in fibrous areola isolated from human spermatozoa. The structure of the carrier is similar to the ADP/ATP exchanger that is present in mitochondria [35]. It is not obvious whether the SFEC occurring in the main part of the tail/flagellum is an ATP carrier or its reservoir. There is a possibility that SFEC has its regions of protein-protein interactions with specific enzymes of the glycolytic pathway. It is suggested that SFEC's direct interaction with glycolytic enzymes can catalyze ATP formation [35]. It seems to be the 
spermatozoa's mechanism of adaptation to decreased oxygen pressure which can occur during spermatozoa movement. Gaining ATP in glycolysis provides the energy essential for that activity. It seems that the described mechanism can explain observations made in this study. Our research showed the ability for progressive movement of those spermatozoa in spite of them losing membrane integrity.

Our data do not show definitely whether the decrease of spermatozoa motility parameters is an indicator of apoptotic changes that occur in cells. If spermatozoa PST was an indicator of cell functioning disturbances, a worsening of the spermatozoa motility parameters would be the natural way of eliminating defective cells from those able to fertilize. In such a case, a significant decrease of the percentage of vital spermatozoa with PST after swim-up selection indicates that this method may be applicable in preparing semen for artificial fertilization.

\section{Conflict of interest None.}

Open Access This article is distributed under the terms of the Creative Commons Attribution Noncommercial License which permits any noncommercial use, distribution, and reproduction in any medium, provided the original author(s) and source are credited.

\section{References}

1. Bretscher MS. Asymmetrical lipid bilayer structure for biological membranes. Nat New Biol. 1972;236:11-2.

2. Bretscher MS. Membrane structure: some general principles. Science. 1973;181:622-9.

3. Rothman JE, Lenard J. Membrane asymmetry. Science. 1977;195:743-53.

4. Daleke DL, Lyles JV. Identification and purification of aminophospholipid flippases. Biochem Biophys Acta. 2000;1486: 108-27.

5. Vance JC, Steenbergen R. Metabolism and functions of phosphatidylserine. Prog Lipid Res. 2005;44:207-34.

6. Fadok VA, Bratton DL, Henson PM. Phagocyte receptors for apoptotic cells: recognition, uptake, and consequences. J Clin Invest. 2001;108:957-62.

7. Matsura T, Togawa A, Kai M, et al. The presence of oxidized phosphatidylserine on Fas-mediated apoptotic cell surface. Biochem Biophys Acta. 2005;1736:181-8.

8. Hoffmann PR, Kench JA, Vondracek A, et al. Interaction between phosphatidylserine and the phosphatidylserine inhibits immune responses in vivo. J Immunol. 2005;174:1393-404.

9. Somersan S, Bhardwaj N. Tethering and tickling: a new role for the phosphatidylserine receptor. J Cell Biol. 2001;155:501-4.

10. Balasubramanian K, Schroit AJ. Aminophospholipid asymmetry: a matter of life and death. Annu Rev Physiol. 2003;65:701-34.

11. Böse J, Gruber AD, Helming L et al. The phosphatidylserine receptor has essential functions during embryogenesis but not in apoptotic cell removal. J Biol. 2004; 3:15

12. Mourdjeva M, Popova Z, Kyurkchiev D, et al. Progesteronemodulated phosphatidylserine externalization in apoptosis and activation of Jurkat cells. Am J Reprod Immunol. 2006;56: 249-57.
13. Van den Eijnde SM, van den Hoff MJ, Reutelingsperger CP, et al. Transient expression of phosphatidylserine at cell-cell contact areas is required for myotube formation. J Cell Sci. 2001;114: 3631-42.

14. Dillon SR, Mancini M, Rosen A, Schlissel MS. Annexin V binds to viable B cells and colocalizes with a marker of lipid rafts upon B cells receptor activation. J Immunol. 2000;164:1322-52.

15. Leytin V, Allen DJ, Mykhaylov S, Lyubimow E, Freedman J. Thrombin-triggered platelet apoptosis. J Thromb Haemost. 2006;4:2656-63.

16. Leung R, Gwozdz AM, Wang H, et al. Persistence of procoagulant surface expression on activated human platelets: involvement of apoptosis and aminophospholipid translocase activity. J Thromb Haemost. 2007;5:560-70.

17. Lopez JJ, Salido GM, Gómez-Arteta E, Rosado JA, Pariente JA. Thrombin induces apoptotic events through the generation of reactive oxygen species in human platelets. J Thromb Haemost. 2007;5:1283-91.

18. Borenstein BYV, Barenholz Y, Hy AE, Rachmilewitz EA, Eldor A. Phosphatidylserine in the outer leaflet of red blood cells from beta-thalassemia patients may explain the chronic hypercoagulable state and thrombotic episodes. Am J Hematol. 1993:44:63-5.

19. Srinivasan PT, Basu J. Altered membrane phospholipid organization and erythrophagocytosis in E beta-thalassemia. Biochim Biophys Acta. 1996;1285:65-70.

20. Bonomini M, Sirolli V, Settefrati N, Dottori S, Di Liberato L, Arduini A. Increased erythrocyte phosphatidylserine exposure in chronic renal failure. J Am Soc Nephrol. 1999;10:1982-90.

21. De Jong K, Larkin SK, Styles LA, Bookchin RM, Kuypers FA. Characterization of the phosphatidylserine-exposing subpopulation of sickle cells. Blood. 2001;98:860-7.

22. Eisele K, Lang PA, Kempe DS, et al. Stimulation of erythrocyte phosphatidylserine exposure by mercury ions. Toxicol Appl Pharmacol. 2006;210:116-22.

23. Lui JCK, Wong JWY, Suen YK, Kwok TT, Fung KP, Kong SK. Cordycepin induced eryptosis in mouse erythrocytes through a $\mathrm{Ca}^{2+}$-dependent pathway without caspase-3 activation. Arch Toxicol. 2007;81:859-65.

24. Schneider J, Nicolay JP, Föller M, Wieder T, Lang F. Suicidal erythrocyte death following cellular $\mathrm{K}^{+}$loss. Cell Physiol Biochem. 2007;20:35-44.

25. Kotwicka M, Filipiak K, Jedrzejczak P, Warchol JB. Caspase-3 activation and phosphatidylserine membrane translocation in human spermatozoa: is there a relationship? Reprod Biomed Online. 2008;16:657-63.

26. Kotwicka M, Jendraszak M, Jendrzejczak P. Phosphatidylserine membrane translocation in human spermatozoa: topography in membrane domains and relations to cell vitality. J Membrane Biol. 2011;24:165-70.

27. World Health Organization laboratory manual for the examination of human semen and sperm-cervical mucus interaction. Cambridge: Cambridge University Press; 1992.

28. Warchoł W, Kotwicka M, Warchoł JB. Kinetic subpopulations of human spermatozoa identification by method of approximation of distribution of spermatozoa motility with distribution ranges. Zool Pol. 2002;47:95-7.

29. Paasch U, Grunewald S, Fitzl G, Glander HJ. Deterioration of plasma membrane is associated with activated caspases in human spermatozoa. J Androl. 2003;24:246-52.

30. Perticarari S, Ricci G, Granzotto M, et al. A new multiparameter flow cytometric method for human semen analysis. Hum Reprod. 2007;22:485-94.

31. Barroso G, Taylor S, Morshedi M, Manzur F, Gaviño F, Oehninger S. Mitochondrial membrane potential integrity and plasma membrane translocation of phosphatidylserine as early apoptotic 
markers: a comparison of two different sperm subpopulations. Fertil Steril. 2006;85:149-54.

32. Ford WCL. Glycolysis and sperm motility: does a spoonful of sugar help the flagellum go round? Hum Reprod Updat. 2006;12:269-74.

33. Krisfelusi M, Miki K, Magyar PL, O’Brien DA. Multiple glycolytic enzymes are tightly bound to the fibrous sheath of mouse spermatozoa. Biol Reprod. 2006;75:270-8.
34. Perl A, Qian Y, Chohan KR, et al. Transaldolase is essential for maintenance of the mitochondrial transmembrane potential and fertility of spermatozoa. Proc Natl Acad Sci USA. 2006;103:14813-8.

35. Kim YH, Haidl G, Schaefer M, Egner U, Mandal A, Herr JC. Compartmentalization of a unique ADP/ATP carrier protein SFEC (Sperm Flagellar Energy Carrier, AAC4) with glycolytic enzymes in the fibrous sheath of the human sperm flagellar principal piece. Dev Biol. 2007;302:463-76. 